\title{
Asosiasi Megabentos dengan Ekosistem Terumbu Karang di Perairan Desa Perlang Bangka Tengah, Bangka Belitung
}

Megabentos Association with Coral Reef Ecosystems in the Waters of Perlang Village Central Bangka, Bangka Belitung

\author{
Arham Hafidh Akbar ${ }^{1 *}$, Sudirman Adibrata ${ }^{1}$, Wahyu Adi ${ }^{1}$ \\ ${ }^{1}$ Program Studi Manajemen Sumberdaya Perairan, Fakultas Pertanian Perikanan dan Biologi, \\ Universitas Bangka Belitung \\ *Email: arham.mspubb@gmail.com
}

\begin{abstract}
This study aims to analyze the density of megabenthos in coral reef ecosystems in the waters of Perlang Village. This research was conducted in November 2019 in the waters of Perlang Village with the megabentos data collection method using the Bentos Belt Transect (BBT) method based on COREMAP CTI LIPI (2017) with 5 data collection stations. The results found 603 individuals consisting of 9 species from 5 megabenthos families in coral reef ecosystems. Species found at the study site are Diadema setosum, Diadema antillarium (Familli Deadematidae), Drupella cornus, Drupella rugosa (Family Murcidae), Trochus sp, Trochus conus(Family Trochidae), Tectus pyramis (Family Tegulidae), Tridacna squamosa, and Tridacna maxima (Family Tridacnidae). The highest attendance percentage of all stations was obtained by Diadema setosum of 47.93\% (289 people). Percentage of live coral cover from 5 observation stations ranged from $57.44 \%$ - 91.78\%. Observation pensions that received the highest percentage of cover values were at pension 2 with $91.78 \%$ in the very good category.
\end{abstract}

Keywords : Density; Megabentos; Coral reef, Perlang village

\section{PENDAHULUAN}

Wilayah Provinsi Kepulauan Bangka Belitung terbagi menjadi wilayah daratan dan wilayah laut dengan total luas wilayah mencapai $81.725,23 \mathrm{~km}^{2}$. Luas daratan lebih kurang 16,424,23 $\mathrm{km}^{2}$ atau 20,10 persen dari total wilayah dan luas laut kurang lebih $65,301,00 \mathrm{~km}^{2}$ atau 79,90 persen dari total wilayah Provinsi Kepulauan Bangka Belitung (BPS Prov. Kep. Babel, 2018). Wilayah laut yang luas membuat Pulau Bangka memiliki ekosistem pesisir yang panjang salah satu wilayah pesisirnya yaitu Perairan Desa Perlang memiliki ekosistem terumbu karang.

Terumbu karang merupakan keanekaragaman hayati yang paling produktuf dan paling kaya, sebagai ekosistem yang memiliki peran sangat penting bagi kelangsungan hidup biota laut (Oktarina et al, 2014; Bangapadang, 2019). Ekosistem terumbu karang merupakan habitat bagi ribuan biota, baik sementara maupun menetap. Terumbu karang memiliki struktur fisik yang rumit, becabang-cabang dan bergua-gua membuat ekosistem ini menarik bagi banyak jenis biota laut bak flora dan fauna. Fungsi ekologi ekosistem terumbu karang diantaranya sebagai habitat (tempat hidup) berbagai macam biota yang berasosiasi seperti hewan bentos (Ferizal, 2011; Fajri, 2014; Lubis, 2016; Cahyadi, 2017, Quanita, 2018). Salah satu biota yang hidup pada ekosistem terumbu karang yaitu megabentos (Thumena et al, 2013; Bangapadang, 2019).Megabentos adalah organisme yang berukuran lebih dari $1 \mathrm{~cm}$ yang hidup di atas atau di dalam dasar laut, meliputi biota menempel, merayap dan meliang serta memiliki peran sebagai sumber bahan makanan bagi organisme yang lain. Megabentos terdiri dari beberapa organisme seperti teripang, kima, lobster, lola, bintang laut berduru, siput drupella, bulu babi dan bintang laut biru (COREMAP LIPI, 2014).
Megabentos dijadikan sebagai indikator pemantauan kondisi kesehatan karang sehingga dibagi menjadi tiga kelompok besar berdasarkan manfaatnya bagi manusia dan ekosistem terumbu karang (COREMAP LIPI, 2014; Bangapadang, 2019).

Perairan Desa Perlang memiliki keanekaragaman hayati laut sehingga dijadikan sumber pencaharian bagi masyarakat yang umumnya bekerja sebagai nelayan dengan cara menjaring, memancing dan melakukan penangkapan dengan cara lain. Kegiatan lain oleh masyarakat yang dapat mengancam ekosistem terumbu karang seperti menjatuhkan jangkar kapal pada ekosistem terumbu karang. Akibat adanya kegiatan masyarakat dan belum adanya penelitian terkait di Perairan Desa Perlang maka perlu diadakannya penelitian tentang kepadatan megabentos pada ekosistem terumbukarang di perairan Desa Perlang Bangka Tengah, Bangka Belitung. Salah satu upaya mengetahui kondisi megabentos dan ekosistem terumbu karang.

\section{METODOLOGI PENELITIAN}

Penelitian dilakukan pada tanggal 9 - 10 November 2019 di Perairan Desa Perlang, Kecamatan Lubuk Besar, Kabupaten Bangka Tengah. Pengambilan sampel yang tersebar 5 stasiun pada ekosistem terumbu karang. Penentuan 5 stasiun berdasarkan COREMAP CTI LIPI (2017) yang mengatakan minimal 3 stasiun dalam satu desa, jadi peneliti menetapkan 5 stasiun pengambilan data. Adapun stasiun pengamatan dapat di lihat pada Gambar 1. 


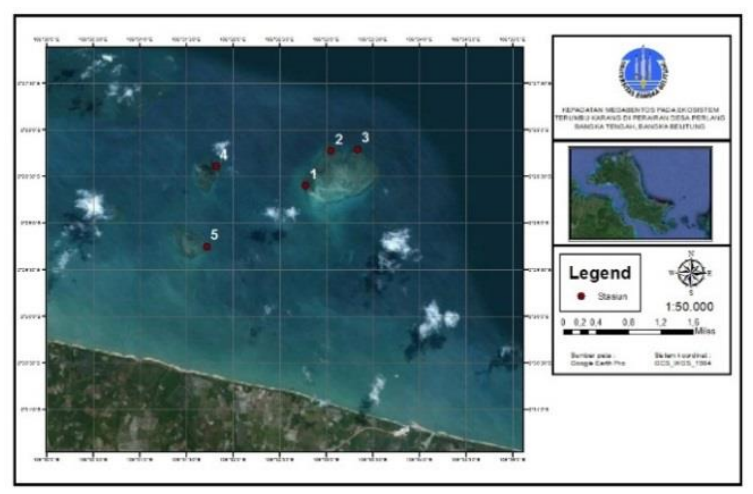

Gambar 1. Peta Lokasi Penelitian

Tabel 1. Koordinat stasiun pengambilan data megabentos

\begin{tabular}{cccc}
\hline \multirow{2}{*}{ Lokasi } & \multirow{2}{*}{ Stasiun } & \multicolumn{2}{c}{ Koordinat } \\
\cline { 3 - 4 } & & LS & BT \\
\hline Gusung & 1 & $02 \circ 28.395^{\prime}$ & $106^{\circ} 32.886^{\prime}$ \\
Perlang & 2 & $02 \circ 28.450^{\prime}$ & $106^{\circ} 32.815^{\prime}$ \\
& 3 & $02 \circ 28.678^{\prime}$ & $106^{\circ} 32.783^{\prime}$ \\
\hline Karang Bugis & 4 & $02^{\circ} 28.375^{\prime}$ & $106^{\circ} 31.839^{\prime}$ \\
\hline Karang & & $02 \circ 29.275^{\prime}$ & $106 \circ 31.733^{\prime}$ \\
\hline Perlang & 5 & &
\end{tabular}

\section{Kepadatan Megabentos}

Pengambilan data terumbu karang menggunakan metode LIT (Line Intersept Transect) dengan cara membentangkan line transect sepanjang $70 \mathrm{~m}$ diarahkan sejajar garis pantai. Pengambilan data megabentos berdasarkan panduan pemantauan megabentos (COREMAP CTI LIPI, 2017) yaitu dengan metode Bentos Belt Transect (BBT) yang merupakan modifikasi dari metode Belt Transect yang dikombinasikan dengan metode Reef Chek Bentos. Metode ini dilakukan dengan cara menarik garis dengan pita berskala (roll meter) sejajar garis pantai dengan panjang transek $70 \mathrm{~m}$. Penggunaan transek 70 $\mathrm{m}$ dilakukan berdasarkan berbagai alasan teknis dilapangan, antara lain kemudahan untuk mempraktikkan, efisiensi waktu, akurasi data yang diperoleh, dan memungkinkan untuk bekerja sama dengan pengambilan data untuk bidang lain menggunakan metode yang mirip (Arbi, 2017). Teknis penarikan garis dengan pantai selalu berada di sebelah kiri penyelam. Selanjtnya pencatatan jeis atau kelompok jenismegabentos target serta jumlah individunya dari titik $0 \mathrm{~m}$ sampai $70 \mathrm{~m}$ dengan lebar pengamatan 1 meter ke kiri dan kanan garis transek. Luasan area pemantauan menjadi $140 \mathrm{~m}^{2}(2 \times 70 \mathrm{~m})$.

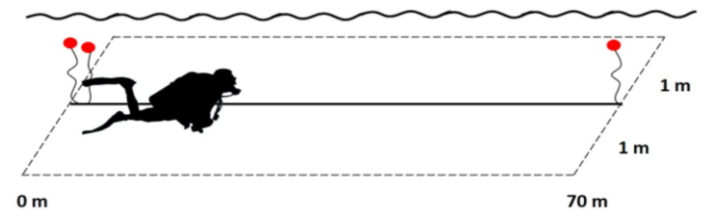

Gambar 2. Skema transek megabentos dengan metode Bentos Belt Transect (COREMAP CTI LIPI,2017)
Megabentos target terdiri dari beberapa organisme seperti teripang, kima, lobster, lola, bintang laut berduru, siput drupella, bulu babi dan bintang laut biru (COREMAP LIPI, 2014).

\section{Analisis Data}

\section{Kepadatan Megabentos}

Kepadatan spesies adalah jumlah individu persatuan luas yang dihitung menggunakan rumus berikut

(Harvey, 2008).

$$
\text { Kepadatan } X=\frac{\text { Jumlah individu } X}{\text { luas belt transect }(140 \mathrm{~m})}
$$

Keterangan:

Kepadatan X

: Kepadatanindividu (ind $/ \mathrm{m}^{2}$ )

Jumlah individu

: Jumlahindividuspesies ke- $i$

Luas belt transect : Luas area pengamatan $140 \mathrm{~m}^{2}$ $(2 \times 70 \mathrm{~m})$

Luas area pengamatan $\left(140 \mathrm{~m}^{2}\right)$ dikonversi ke satuan ha (hektar) dengan tujuan mempermudah pembacaan data (Keterangan : 1 ha $=10.000 \mathrm{~m}^{2}$ ).

\section{Persentase Tutupan Terumbu Karang}

Nilai persentase penutupan terumbu karang diperoleh dari hasil pengukuran lifeform karang dengan menggunakan rumus (English et al., 1994) :

$$
L=\frac{L i}{N} \times 100 \%
$$

Keterangan :

$\mathrm{L}$

$\mathrm{Li}$

$\mathrm{N}$

$$
\begin{aligned}
& \text { : persentase penutupan karang }(\%) \\
& \text { : panjang lifeform (intercept koloni) } \\
& \text { jenis kategori ke-i } \\
& : \text { panjang transek }(70 \mathrm{~m})
\end{aligned}
$$

Persentase tutupan adalah persentase luas area yang ditutupi oleh pertumbuhan karang. Persentase tutupan diperoleh dengan mengukur intercept koloni karang yang dilewati garis transek. Jumlah panjang intercept koloni karang sepanjang garis transek dibagi dengan panjang transek $\times 100 \%$ memberikan nilai persentase tutupan. Kondisi terumbu karang berdasarkan persen tutupan karang hidup menurut KepMen LH No.4 Tahun 2001 tentang Baku Mutu Kerusakan terumbu Karang adalah :

$$
\begin{array}{ll}
-\quad \text { Sangat baik } & =75 \%-100 \% \\
-\quad \text { Baik } & =50 \%-74,9 \% \\
-\quad \text { Sedang } & =25 \%-49,9 \% \\
-\quad \text { Buruk } & =0 \%-24,9 \%
\end{array}
$$




\section{HASIL DAN PEMBAHASAN}

\section{Kepadatan Megabentos}

Jumlah seluruh megabentos yang ditemukan pada 5 stasiun pengamatan di perairan Desa Perlang yaitu total terdapat 603 individu yang terdiri dari 9 spesies dari 5 famili. Terdapat 9 spesies megabentos yang ditemukan yaitu Diadema setosum, Diadema antillarium (Familli Deadematidae), Drupella cornus, Drupella rugosa (Famili Murcidae), Trochus niloticus, Trochus conus (Famili Trochidae), Tectus pyramis (Famili Tegulidae), Tridacna squamosa, dan Tridacna maxima (Famili Tridacnidae). Megabentos target dengan kehadiran spesies megabentos seperti yang disajikan pada tabel berikut.

Tabel 2. Hasil kepadatan megabentos individu/ha

\begin{tabular}{lccccc}
\hline \multicolumn{1}{c}{ Spesies } & \multicolumn{2}{c}{ Gusung Perlang } & $\begin{array}{c}\text { Karang } \\
\text { Bugis }\end{array}$ & $\begin{array}{c}\text { Karang } \\
\text { perlang }\end{array}$ \\
\cline { 2 - 6 } & $\mathbf{1}$ & $\mathbf{2}$ & $\mathbf{3}$ & $\mathbf{4}$ & $\mathbf{5}$ \\
\hline Famili Deadematidae & & & & & \\
Diadema setosum & 3.714 & 929 & 1.929 & 12.000 & 2.017 \\
Diadema antillarium & 0 & 0 & 0 & 0 & 500 \\
\hline Famili Murcidae & & & & & \\
Drupella cornus & 5.214 & 8.714 & 0 & 0 & 0 \\
Drupella rugosa & 0 & 0 & 492 & 500 & 857 \\
\hline $\begin{array}{l}\text { Famili Trochidae } \\
\text { Trochus niloticus }\end{array}$ & 786 & 286 & 0 & 1.429 & 571 \\
Trochus conus & 0 & 214 & 0 & 0 & 643 \\
Famili Tegulidae & & & & & \\
Tectus pyramis & 0 & 500 & 0 & 1.500 & 0 \\
\hline Famili Tridacnidae & & & & & \\
Tridacna squamosa & 0 & 0 & 214 & 0 & 0 \\
Tridacna maxima & 0 & 0 & 71 & 0 & 0 \\
\hline
\end{tabular}

Hasil yang disajikan dari tabel individu tiap spesies megabentos yang didapatkan di seluruh stasiun penelitian, terdapat 2 spesies yang megabentos yang ditemukan pada tiap stasiun. Kedua spesies megabentos target tersebut yaitu Diadema setosum dan Drupella Spp.

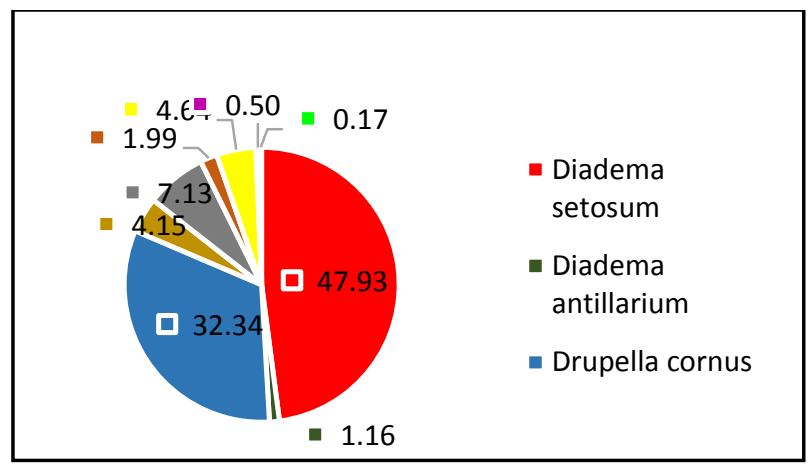

Gambar 3. Diagram perbandingan jumlah individu dari masing-masing spesies megabentos target di perairan Desa Perlang

Hasil dari diagram diatas berasal dari seluruh stasiun pengambilan data yang berjumlah 5 stasiun. Terlihat bahwa terdapat dua spesies yang ditemukan dalam jumlah mendominasi. Kedua spesies tersebut yaitu Diadema setosum dan Drupella cornus, dengan persentase Diadema setosum sebanyak 47,93\% (289 individu) dan Drupella cornus sebanyak 32,34\% (195 individu). Jumlah megabentos yang ditemukan dalam jumlah sedang antara lain Drupella rugosa sebesar 4,15\% (25 individu), Trochus sp. sebanyak 7,13\% (43 individu), Trochus conus sebanyak 1,99\% (12 individu), dan Tectus pyramis sebanyak 4,63\% (28 individu). Spesies megabentos lain yang ditemukan dalam jumlah yang sedikit yaitu, Diadema antillarium sebanyak $1,16 \%$ (7 individu), Tridacna squamosa sebanyak $0,50 \%$ (3 individu), dan Tridacna maxima sebanyak $0,17 \%$ ( 1 individu).

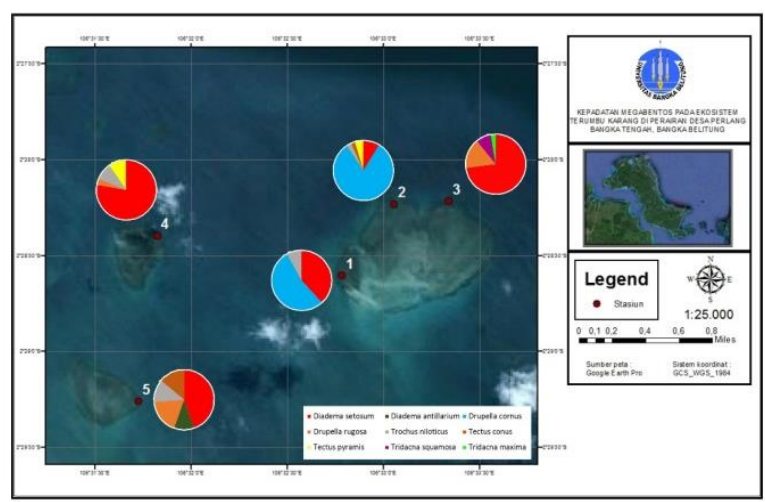

Gambar 4. Diagram persentase kehadiran megabentos pada masing-masing stasiun di perairan Desa Perlang

Dilihat dari persentase kehadiran masingmasing spesies fauna megabentos pada tiap stasiun, terlihat stasiun 1 memiliki jenis megabentos yang paling sedikut yaitu 3 jenis megabentos. Stasiun yang memiliki jumlah jenis megabentos paling banyak yaitu terdapat di stasiun 2 dan 5 dengan lima spesies megabentos. Keberadaan setiap spesies megabentos tidak lepas dari kondisi terumbu karang sebagai habitat dari berbagai jenis fauna megabentos pada masingmasing megabentos target. secara ekologi terumbu karang juga menjaga keseimbangan kehidupan bagi biota yang hidup disekitarnya (Soraya, 2013). Menurut Nontji (2002), bentos memanfaatkan terumbu karang sebagai tempat tinggalnya, jenis ekinodermata seperti 
bulu babi, bintang laut dan jenis lainnya mempunyai tempat hidup pada daerah terumbu karang dan celahcelah terumbu karang.

Beberapa jenis megabentos yang ditemukan memiliki peran masing masing seperti sebagai parasit terumbu karang, menguntungkan terumbu karang, dan memiliki nilai ekonomis. Megabentos yang bersifat parasitisme seperti Drupella spp., ada pula yang bersifat menguntungkan bagi terumbu karang seperti bulu babi yang berperan dalam membersihkan algae. Bulu babi dapat berperan dalam pemulihan kondisi ekosistem terumbu karang yang berkompetisi dengan pertumbuhan algae. Terdapat pula megabentos yang memiliki nilai ekonomis tinggi di lokasi penelitian yaitu keong Lola yang mana dalam pengambilan data ditemukan dari famili Trochidae yaitu Trochus sp., Trochus conus, dan famili Tegulidae Tectus pyramis, selain dagingnya dapat dimakan dan cangkangnya dapat dijadikan sebagai bahan baku pembuatan kancing baju dan perhiasan, dapat juga sebagai perangsang pembebntukan mutiara pada budidaya kerang mutiara (COREMAP CTI LIPI, 2017).

\section{Persentase Tutupan Terumbu Karang}

Tutupan ekosistem terumbu karang di Perairan Desa Perlang setelah dilakukan analisis tingkat lifeformdidapatkan 4 stasiun dengan kategori sangat baik yaitu stasiun 1,2,4, dan 5 dengan nilai $77,8 \%$ $91,78 \%$, sedangkan untuk stasiun 3 dalam kategori baik dengan nilai $57,44 \%$. Penentuan kondisi terumbu karang berdasarkan persen tutupan karang hidup menurut KepMen LH No.4 Tahun 2001 tentang Baku Mutu Kerusakan terumbu Karang. Data ditampilkan pada tabel berikut :

Tabel 3. Persentase tutupan karang hidup

\begin{tabular}{cccl}
\hline Lokasi & Stasiun & Tutupan Karang Hidup (\%) & \multicolumn{1}{c}{ Kategori } \\
\hline \multirow{3}{*}{ Gusung Perlang } & 1 & 90 & Sangat baik \\
& 2 & 91,78 & Sangat baik \\
& 3 & 57,44 & Baik \\
\hline Karang Bugis & 4 & 79,51 & Sangat baik \\
\hline Karang Perlang & 5 & 77,80 & Sangat baik \\
\hline
\end{tabular}

Persentase tutupan karang hidup di perairan Desa Perlang dengan rata-rata 79,3 dikategorikan sangat baik menurut Keputusan Mentri Lingkungan Hidup No.4 Tahun 2001 tentang Baku Mutu Kerusakan terumbu Karang. Terdapat empat stasiun yang setelah dilakukan analisis memperoleh kategori sangat baik, yaitu stasiun 1,2,4, dan 5. Stasiun 1 mendapatkan nilai persentase tutupan karang hidup 90\%. Stasiun 2 mendapatkan nilai persentase tutupan karang hidup 91,78\%. Stasiun 4 mendapatkan nilai persentase tutupan karang hidup 79,51\%. Stasiun 5 mendapatkan nilai persentase tutupan karang hidup $77,8 \%$. Sedangkan stasiun yang memperoleh nilai tutupan karang hidup 57,44\% yang masuk dalam kategori baik. Hubungan megabentos dan terumbu karang menggunakan analisis korelasi didapatkan nilai korelasi $r=0,629$ masuk dalam kriteria korelasi hubungan sangat kuat.

Kondisi terumbu karang di perairan Desa Perlang dapat dikatakan bahwa perairan tersebut memiliki tingkat kesehatan karang yang baik dan sangat baik. Hal ini disebabkan oleh penetrasi cahaya yang masuk kedalam kolom perairan sehingga zooxanthellae dapat melakukan proses fotosintesis dapat juga pengaruh dari faktor fisika kimia perairan yang sangat mendukung (Fajri, 2014). Hasil tersebut sesuai dengan pernyataan Suharsono (2008) yang menyatakan bahwa terumbu karang merupakan salah satu ekosistem perairan tropis yang memiliki fungsi yang sangat penting baik bagi organisme yang membangun ekosistem ini ataupun ekosistem yang ada disekitarnya.

\section{KESIMPULAN DAN SARAN}

\section{Kesimpulan}

Jumlah seluruh megabentos yang ditemukan di perairan Desa Perlang yaitu total terdapat 603 individu yang terdiri dari 9 spesies dari 5 famili. Terdapat 9 spesies megabentos yang ditemukan yaitu Diadema setosum, Diadema antillarium (Familli Deadematidae), Drupella cornus, Drupella rugosa (Famili Murcidae), Trochus niloticus, Trochus conus (Famili Trochidae), Tectus pyramis (Famili Tegulidae), Tridacna squamosa, dan Tridacna maxima (Famili Tridacnidae). Kepadatan paling besar diperoleh Diadema setosum pada stasiun 4 dengan nilai 12.000 individu/ha. Nilai persentase dari jumlah total kehadiran spesies tertinggi terdapat pada spesies Diadema setosum dengan persentase sebesar 47,93\% (289 individu). Jumlah spesies paling banyak hadir di stasiun 2 dan 5 dengan jumlah lima spesies. Persentase tutupan terumbu karang hidup dari 5 stasiun pengamatan berkisar antara $57,44 \%$ - 91,78\%. Satsiun pengamatan yang mendapatkan nilai persentase tutupan paling tinggi yaitu pada satsiun 2 dengan 91,78\% dalam kategori sangat baik, dan stasiun dengan persentase tutupan paling rendah pada stasiun 3 dengan persentase $57,44 \%$ dalam kategori baik.

\section{Saran}

Megabentos merupakan biota asosiasi dengan ekosistem terumbu karang yang mempunyai fungsi ekologis, ekonomis dan ada sebagai parasit terumbu karang. Terdapat biota yang memiliki nilai ekonomis tinggi dari famili Trochidae yang dapat dimanfaatkan 
secara bijak dan famili Tridacnidae yang merupakan salah satu biota yang dilindungi berdasarkan Peraturan Pemerintah No.7 Tahun 1999 maka perlu dilakukan pembagian zona pemanfaatan dan zona perlindungan sebagai upaya melindungi biota yang dalam status dilindungi.

\section{DAFTAR PUSTAKA}

Arbi UY, Aji LP, Suetiono. 2017. Modul Pelatihan Penilaian Kondisi Megabentos "B"Pengambilan Data Megabentos. COREMAP-CTI. P2O LIPI: Jakarta Utara

Bangapadang M, Emiyarti, dan Nurgayah W. 2019. Kepadatan dan Keanekaragaman Megabentos Berdasarkan Persentase Tututpan Karang di Perairan Desa Buton, Kecamatan Bungku Selatan, Kabupaten Morowali, Sulawesi Tengah. Jurnal Sapa Laut. Vol. 4(2):89-97

BPS Provinsi Kepulauan Bangka Belitung. 2018. Provinsi Kepulauan Bangka Belitung Dalam Angka 2018. BPS Provinsi Kepulauan Bangka Belitung. ISSN: 1693-086X

Cahyadi O. 2016. Asosiasi Makrozoobentos (Non Karang) Nokturnal Dengan Terumbu Karang Di Perairan Turun Aban Sungailiat Dan Pulau Ketawai [skripsi]. Bangka: Fakultas Pertanian, Perikanan dan Biologi, Universitas Bangka Belitung

COREMAP II LIPI. 2014. Panduan Monitoring Kesehatan Terumbu Karang

COREMAP CTI. 2017. Panduan Pemantauan Megabentos. Lembaga Penelitian Ilmu Pengetahuan. Jakarta. ISBN 978-602-6504-12-8

English SC, Wilkinson, and V Barker.1994. Survey Manual for Tropical Marine Resources. ASEAN-Australian Marine Project. Australia.

Fajri MA. 2014. Asosiasi Makrozoobentos dengan Terumbu Karang. [skripsi]. Universitas Bangka Belitung

Ferizal J. 2011. Kelimpahan Bulu Babi (Diadema setosum) di Karang Kering Rebo, Kabupaten Bangka [skripsi]. Bangka: Fakultas Pertanian Perikanan dan Biologi, Universitas Bangka Belitung.

Harvey JT. 2008.Abundance Encyclopedia of Ecology. ed. by S.E.J. Fath and D. Brian, pp. 4-10. Academic Press, Oxford.

Keputusan Menteri Negara Lingkungan Hidup. Nomor 4 Tahu 2001. Tentang : Kriteria Baku Kerusakan Terumbu Karang.

Lubis SA. 2016. The Sea Urchin (Echinoidea) from Panjang Island Water, Bangka Belitung Province. Jurnal Omni Akuatika 12(2):125-129

Nontji A. 2002. Laut Nusantara. Jakarta : Djambatan

Oktarina A, Kamal E, Suparno. 2014. Kajian KondisiTerumbu Karang dan Straegi
Pengelolaannya di Pulau Panjang, Air Bangis, Kabupaten Pasaman Barat. Jurnal Natur Indonesia. Vol. 16(1) : 2331.

Peraturan Pemerintah Republik Indonesia Nomor 7 Tahun 1999 Tentang Pengawetan Jenis Tumbuhan Dan Satwa Presiden Republik Indonesia

Quanita I. 2018. KepadatanEchinodermata pada Ekosistem Terumbu Karang di Perairan Pulau Ketawai dan Gusung Asam, Bangka Tengah. [skripsi]. Program Studi Manajemen Sumberday Perairan. Fakultas Pertanian Perikanan dan Biologi. Universitas Bangka Belitung

Soraya I. 2013. Keragaman Makroinvertebrata di Kawasan Terumbu Karang di Perairan Laut Aceh Besar. [Skripsi]. Universitas Syiah Kuala Darusalam, Banda Aceh

Suharsono. 2008. Jenis-jenis Karang di Indonesia. Jakarta: LIPI Press

Tuhumena JR, Kusen JD, Paruntu CP.2013. Struktur Komunitas Karang dan Biota Asosiasi Pada Kawasan Terumbu Karang di Perairan Desa Minanga Kecamatan Malayang II dan Desa Mokupa Kecamatan Tombariri. Jurnal Pesisir dan Laut Tropis. Vol. 3(1). 